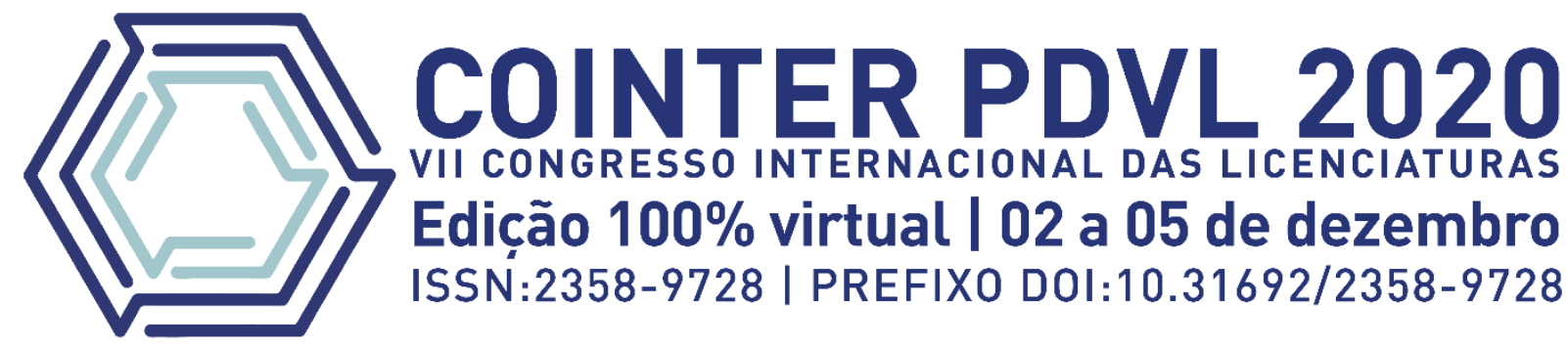

\title{
A GENÉTICA DO ENSINO MÉDIO NA PERSPECTIVA DISCENTE: UM ESTUDO DE CASO NO MUNICÍPIO DE URUÇUÍ-PI
}

\section{LA GENÉTICA DEL \\ ESCUELA SECUNDARIA EN PERSPECTIVA DISCENTE: UN ESTUDIO DE CASO EN LA CIUDAD DE URUÇUÍ-PI}

\section{THE GENETICS OF HIGH SCHOOL IN THE DISCENT PERSPECTIVE: A CASE STUDY IN THE CITY OF URUÇUÍ-PI}

\author{
Apresentação: Comunicação Oral \\ Kêmmia Alves Aguiar ${ }^{1}$; Ícaro Fillipe de Araújo Castro ${ }^{2}$ \\ DOI: https://doi.org/10.31692/2358-9728.VIICOINTERPDVL.0270
}

\begin{abstract}
RESUMO
A disciplina Biologia detém diversas áreas que, em conjunto, estudam a vida em seus diferentes contextos. Ao abordar a hereditariedade, ética e manipulação gênica, a Genética se mostra como um importante componente curricular e é considerada difícil pela maioria dos estudantes, que muitas vezes, possui um aprendizado limitado dessa importante área. Por isso, o presente artigo objetivou conhecer as perspectivas e dificuldades de concluintes do Ensino Médio da rede escolar pública de Uruçuí-PI, relacionadas aos conteúdos de Genética. Para cumprimento dos objetivos, a pesquisa foi realizada a partir de uma abordagem qualitativa em turmas de $3^{\circ}$ ano. A participação no referido estudo limitou-se a discentes que já tinham visto os conteúdos de genética em suas respectivas escolas, com participação total de 32 estudantes. Todos os participantes concordaram com um Termo de Consentimento Livre e Esclarecido e a coleta de dados se deu por meio de questionários utilizando-se a plataforma google forms. Nas respostas, a maioria dos estudantes afirmou ter dificuldades nos conteúdos relacionados à genética, sendo a principal delas os cálculos matemáticos. Afirmaram ainda, que não participam de atividades lúdicas, apesar de considerá-las ferramentas favoráveis para melhoria do ensino. Dessa forma, faz-se necessário que as metodologias utilizadas para aplicação dos conteúdos de genética sejam repensadas para proporcionarem aos estudantes uma aprendizagem efetiva de modo que compreendam e consigam aplicar tais conhecimentos. Espera-se também que os resultados aqui apresentados sirvam de diagnóstico para propostas educacionais de melhoria no processo de ensinoaprendizagem das diversas disciplinas de Biologia, com ênfase nos conteúdos de genética.

Palavras-Chave: Genética, Ensino-aprendizagem, Dificuldades de aprendizagem.
\end{abstract}

\section{RESUMEN}

La disciplina Biología tiene varias áreas que, juntas, estudian la vida en sus diferentes contextos. Al abordar la herencia, la ética y la manipulación genética, la genética es un componente curricular

\footnotetext{
${ }^{1}$ Curso de Licenciatura em Ciências Biológicas, Instituto Federal de Educação, Ciência e Tecnologia do Piauí Campus Uruçuí, kemmiaalves@ outlook.com

${ }^{2}$ Doutor em Biologia Celular e Molecular Aplicada, Instituto Federal de Educação, Ciência e Tecnologia do Piauí - Campus Uruçuí, icaro.castro@ifpi.edu.br
} 
importante y la mayoría de los estudiantes la consideran difícil, quienes a menudo tienen un aprendizaje limitado en esta importante área. Por tanto, este artículo tuvo como objetivo conocer las perspectivas y dificultades de los egresados de la escuela secundaria de la red de escuelas públicas de Uruçuí-PI, relacionadas con los contenidos de Genética. Para cumplir con los objetivos, la investigación se realizó desde un enfoque cualitativo en clases de 3er año. La participación en este estudio se limitó a alumnos que ya habían visto los contenidos de genética en sus respectivas escuelas, con una participación total de 32 alumnos. Todos los participantes aceptaron un formulario de consentimiento libre e informado y los datos se recopilaron a través de cuestionarios utilizando la plataforma de formularios de Google. En las respuestas, la mayoría de los estudiantes dijo tener dificultades en los contenidos relacionados con la genética, siendo la principal los cálculos matemáticos. También manifestaron que no participan en actividades recreativas, a pesar de considerarlas como herramientas favorables para mejorar la docencia. Por ello, es necesario que se replanteen las metodologías utilizadas para aplicar los contenidos de la genética para brindar al alumno un aprendizaje efectivo para que comprenda y logre aplicar dicho conocimiento. También se espera que los resultados aquí presentados sirvan de diagnóstico para propuestas educativas de mejora en el proceso de enseñanza-aprendizaje de las distintas disciplinas de la Biología, con énfasis en el contenido de la genética.

Palabras Clave: Genética, Enseñanza-aprendizaje, Dificultades de aprendizaje.

\section{ABSTRACT}

The Biology subject comprises several areas, which together study life in its different contexts. By approaching heredity, ethics and gene manipulation, Genetics has shown itself to be an important curricular component, and it is considered difficult by most students, who frequently obtain a limited learning of this important area. Therefore, this article aims to explore the perspectives and difficulties of High School graduates of the public-school system of Uruçuí, Piaui, Brazil, in relation to contentes of the Genetics subject. In order to achieve the objectives of this study, a research was carried out through a qualitative approach with third-year classes of public schools of the aforementioned municipality that provide High School education. The participation in this study was limited to students who had been previously exposed to genetics-related topics at their respective schools, with a total participation of 32 students. All participating students agreed with the Term of Free and Informed Consent. The data collection took place through questionnaires by using the google forms platform. On their answers, most student affirmed to have difficulties with genetics-related topics, with math calculations standing out as the main one. The respondents also affirmed that they do not participate at ludic activities, although they are considered to be tools that enables a better learning. In conclusion, it is necessary to rethink the methodologies used to teach genetics-related topics in order to provide students with an effective learning so that they understand and are able to apply such knowledge. It is also sought that the results presented in this paper serve as a diagnosis for educational proposals aimed at the improvement of the teaching-learning process of different Biology-related subjects, with emphasis in genetics contentes.

Keywords: Genetics, Teaching-learning, Learning difficulties.

\section{INTRODUÇÃO}

A Biologia é uma ciência que abrange todas as formas de vida desde a origem à decomposição, passando por suas expressões, interações e diversos outros aspectos e se apresenta de forma bem ampla; encontra-se dividida em vários ramos, todos voltados a uma parte específica da ciência. Dessa forma, apreendendo a importância e complexidade dessa ciência, a eficácia do seu processo de ensino aprendizagem passa pela forma dinâmica à qual ela é abordada na sala de aula (GOULART; FARIA, 2014). 
A Genética, campo de estudo da hereditariedade e ramo da Biologia norteia os princípios da transmissão de caracteres presentes nos genes, compartilhados ao longo das gerações e está fundamentada nos estudos de Gregor Mendel que postulou duas leis acerca da hereditariedade (COSTA, 2019). Nesse contexto, os Parâmetros Curriculares Nacionais do Ensino Médio (PCNEM) assinalam como um dos temas estruturadores do ensino de Biologia a "Transmissão da vida, ética e manipulação gênica", no qual a genética pode ser trabalhada a partir de unidades temáticas: fundamentos da hereditariedade; genética humana e saúde; aplicações da engenharia genética; e benefícios e perigos da manipulação genética (BRASIL, 2002).

Como componente curricular da disciplina de Biologia, a Genética é considerada difícil pelos discentes em função da sua complexidade (ARAÚJO; CARVALHO; LIMA, 2016). Pesquisas como a de Araújo et al. (2018) realizadas em instituições públicas de ensino demostram que as dificuldades de estudantes do ensino médio estão relacionadas em sua maioria com a terminologia cientifica, a presença de cálculos matemáticos, distanciamento da realidade em que vivem, ausência de aulas práticas, atividades lúdicas e estrutura física da instituição de ensino.

Duré, Andrade, Abílio (2018), evidenciaram a importância da contextualização no ensino, já que a inclusão de aspectos relacionados à vida dos alunos tem como objetivo melhorar não só sua aprendizagem dos conteúdos, mas também sua percepção e relação com sua realidade. A utilização dos conhecimentos científicos aprendidos poderá proporcionar tomadas de decisões mais críticas e melhor fundamentadas, percebendo as consequências de suas ações, superando assim o aspecto técnico do aprendizado, alcançando a aplicabilidade dos temas (DURÉ; ANDRADE; ABÍLIO, 2018).

Diante das premissas destacadas, a hipótese proposta nesse estudo é que a complexidade dos conteúdos de Genética e/ou práticas pedagógicas e didáticas utilizadas por docentes, dificulta a aprendizagem dos conteúdos pelos estudantes e, consequentemente, leva a um baixo desempenho acadêmico; situação está que pode ser amenizada com a utilização de estratégias de ensino que visem enfatizar aspectos lúdicos e interativos, de modo a tornar a aprendizagem significativa, tendo em vista sua importância na educação cientifica dos alunos.

A partir de tais considerações, o presente artigo objetivou conhecer as perspectivas e dificuldades de concluintes do Ensino Médio da rede escolar pública de Uruçuí-PI, relacionadas aos conteúdos de Genética. Como objetivos específicos, destacamos: levantar dados sobre a percepção de estudantes a respeito dos conteúdos de Genética na disciplina de Biologia; identificar as dificuldades dos estudantes na aprendizagem dos conteúdos de 


\section{A GENÉTICA DO ENSINO MÉDIO NA PERSPECTIVA DISCENTE}

genética; reconhecer os conteúdos de maior dificuldade estudados em Genética; verificar se os professores e professoras utilizam aulas/atividades didáticas que contribuam no processo de ensino-aprendizagem desse ramo de conhecimento.

\section{FUNDAMENTAÇÃO TEÓRICA}

A genética é a ciência da hereditariedade e o ramo da biologia que estuda os mecanismos de transmissão das características de uma geração para outra, além das variações que ocorrem na transmissão e sua importância (TEXEIRA; NASCIMENTO, 2020). Segundo Borges, Silva, Reis (2016) a genética é uma das áreas do ensino mais abrangentes, podendo ser classificada com um conteúdo transdisciplinar, onde engloba a matemática, a física, a interpretação, a lógica, a razão, entre vários outros fatores que norteiam o seu estudo.

Destacando-se por meio da medicina e da engenharia genética, essa ciência tem sido ressaltada na atualidade, conquistando grade visibilidade no meio cientifico e popular, sendo frequentemente discutida (ARAÚJO et al., 2018). É importante que os conteúdos de Genética sejam compreendidos, pois por é meio destes que novas pesquisas, avanços científicos e tecnológicos são apresentados aos estudantes.

Tais conhecimentos permitem que os estudantes participem de debate com questões éticas, morais, políticas e econômicas das manipulações genéticas, analisando-as e avaliando os riscos e benefícios para a sociedade e o meio ambiente (LA LUNA, 2014). Rocha (2013) afirma que o ensino de Genética tem sido considerado de extrema importância para a alfabetização científica, que junto aos instrumentos da mídia e da divulgação científica exerce o papel complementar ao levantar questões polêmicas, direcionando para a democratização do conhecimento e para a discussão dos caminhos da legislação e de desenvolvimento da sociedade.

As temáticas de genética fazem parte do conteúdo de biologia ensinado no $3^{\mathrm{a}}$ ano do ensino médio, como disposto nos Parâmetros Curriculares Nacionais do Ensino Médio (PCNEM). Trabalhada a partir de unidades temáticas, o estudo de genética depende da compreensão de termos básicos como DNA, cromossomo, genoma, clonagem (BRASIL, 2002). Porém, a genética, não é bem aceita pela maioria dos estudantes em função de sua complexidade (ARAÚJO; CARVALHO; LIMA, 2016).

No decorrer do processo de ensino-aprendizagem a atuação pedagógica do professor torna-se um instrumento importante no desenvolvimento de estratégias para o ensino lúdico de Genética e permite o bom desempenho dos estudantes na aprendizagem (MASCARENHAS et al., 2016). Os docentes, em sua maioria, destacam a ausência de 
materiais didáticos, a precariedade da estrutura física nas instituições, deficiências na formação e dificuldades na formação continuada como principais dificuldades para o ensino de genética (LEAL; MEIRELLES; RÔÇAS, 2019; FERREIRA et al., 2015).

As Dificuldades em aprender genética são atribuídas em suma aos conceitos abordados em genética, devido a difícil assimilação destes, necessitando de métodos que auxiliem os estudantes no entendimento (ARAUJO; GUSMÃO, 2017). Por conseguinte, Rocha (2013) afirma que distintas áreas podem e devem ser exploradas pensando em uma melhor qualidade de ensino através de metodologias diferenciadas e novas propostas pedagógicas. A partir de materiais didáticos os estudantes aprendem a associar o seu conhecimento com o cotidiano e aplicá-lo.

\section{METODOLOGIA}

Esta pesquisa possui abordagem qualitativa, sendo caracterizada como pesquisa de natureza aplicada e descritiva quanto aos objetivos (PRODANOV; FREITAS, 2013). Desenvolvida em escolas públicas do município de Uruçuí-PI, em turmas de $3^{\circ}$ ano do Ensino Médio, uma vez que os conteúdos de genética são trabalhados nessa etapa educacional.

Das escolas selecionadas, três pertencem a Rede Estadual de ensino e uma pertence a Rede Federal. A princípio, dez turmas participariam da pesquisa, contudo, um dos critérios de participação era a exigência de que os participantes já tivessem visto os conteúdos de genética, e por isso, 5 turmas foram excluídas dessa pesquisa, sobrando assim 5 turmas, perfazendo um total 32 estudantes, conforme apresentado no Quadro 01.

Quadro 01. Turmas de $3^{\circ}$ do Ensino Médio de Uruçuí, participantes e não participantes da pesquisa.

\begin{tabular}{|c|c|c|c|}
\hline Rede & Escola & Turma & Participação \\
\hline \multirow{4}{*}{ Estadual } & \multirow{2}{*}{ Escola A } & Turma A1 & Sim \\
\cline { 2 - 4 } & & Turma A2 & Sim \\
\cline { 2 - 4 } & \multirow{3}{*}{ Escola B } & Turma B1 & Não \\
\cline { 3 - 4 } & & Turma B2 & Não \\
\cline { 2 - 4 } & \multirow{2}{*}{ Escola C } & Turma B3 & Sim \\
\cline { 3 - 4 } & & Turma C1 & Não \\
\cline { 2 - 4 } Federal & \multirow{3}{*}{ Escola D } & Turma C2 & Sim \\
\cline { 3 - 4 } & & Turma D1 & Sim \\
\hline & & Turma D2 \\
\hline
\end{tabular}

Fonte: Própria (2020).

Para realização deste trabalho, inicialmente os discentes foram esclarecidos sobre os objetivos e perspectivas da pesquisa e convidados a participarem. Ao aceitarem participar de forma voluntária, eles assinaram um Termo de Consentimento Livre e Esclarecido (TCLE), no qual os assegurava o anonimato na pesquisa, retirada de seus dados caso desejassem, bem 


\section{A GENÉTICA DO ENSINO MÉDIO NA PERSPECTIVA DISCENTE}

como permitia aos pesquisadores a publicação dos resultados obtidos.

Para coleta de dados, optou-se por questionário desenvolvido pela plataforma online Google Forms ${ }^{\circledR}$, que permite as respostas por meios virtuais e disponibiliza os dados na forma de gráficos, facilitando a visualização e análise de dados. Essa escolha se deu diante a pandemia global de COVID-19 declarada pela Organização Mundial da Saúde (OMS, 2020), exigindo questionários online como uma forma de seguir as medidas preventivas e manter a segurança dos pesquisadores e participantes.

O questionário é uma ferramenta de levantamento de dados que valoriza a descrição verbal do público-alvo e deve ser simples e direto para que os respondentes o compreendam com clareza (PRODANOV; FREITAS, 2013). O questionário da presente pesquisa foi composto por oito questões de múltipla escolha que buscavam compreender as percepções dos estudantes acerca das principais dificuldades no ensino de genética. Os resultados foram submetidos à análise qualitativa. Os temas das questões seguem apresentados no Quadro 02.

Quadro 02. Temas das questões presentes no questionário.

\begin{tabular}{|c|c|}
\hline Questão & Tema \\
\hline 1 & Nível de dificuldade na disciplina de biologia \\
\hline 2 & Nível de dificuldade nos conteúdos de genética \\
\hline 3 & Causas da dificuldade em aprender genética \\
\hline 4 & Satisfação nos conteúdos de genética em relação aos demais \\
\hline 5 & Aprendizagem nas aulas de genética \\
\hline 6 & Conteúdo de maior dificuldade na genética \\
\hline 7 & Participação em atividades com metodologias lúdicas \\
\hline 8 & Opinião sobre atividades com metodologias lúdicas \\
\hline
\end{tabular}

Fonte: Própria (2020).

\section{RESULTADOS E DISCUSSÃO}

Dos 32 estudantes participantes da pesquisa, 20 (62,5\%) eram do sexo feminino e 12 $(37,5 \%)$ do sexo masculino, com faixa etária variando entre 16 e 22 anos de idade. A maioria do grupo amostral pertence à Rede Federal de Ensino, com o total de 20 (62,5\%) participantes e $12(37,5 \%)$ são alunos regularmente matriculados na Rede Estadual de Ensino.

$\mathrm{Na}$ primeira pergunta, indagou-se aos discentes sobre o nível de dificuldade vivenciada por eles na disciplina de biologia. Nas respostas observadas na figura 1, 30 alunos $(93,8 \%)$ relataram que a disciplina é "um pouco difícil”, um aluno $(3,1 \%)$ relatou ser "muito difícil" e um discente relatou ser "Fácil" (3,1\%). As respostas obtidas deixam claro as dificuldades relacionadas ao ensino da biologia que pode estar relacionada a diversos fatores.

Um estudo realizado por Lima e Santos (2014), na cidade de Guaralhuns, em escolas públicas, com a finalidade de produzir um aplicativo no formato de jogo, demonstrou que 
fatores como: memorização, excesso de conteúdo, ausência de contextualização e aulas práticas, dificultam o processo educativo, interferindo negativamente no ensino de biologia. Esses fatos apontam um ensino com prevalência de aulas expositivas, vinculado à falta de metodologias inovadoras, desmotivando os estudantes a aprenderem os conteúdos de Biologia.

Figura 1: Nível de dificuldade relacionada a disciplina de Biologia.

32 respostas

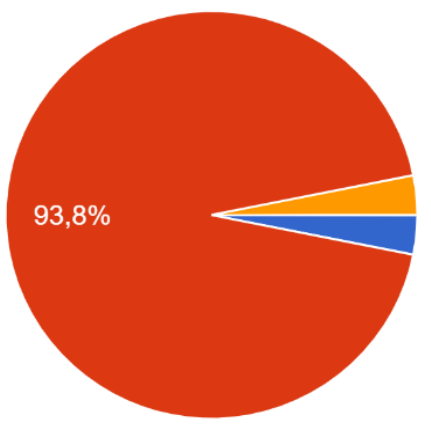

Muito difícil;

Um pouco difícil;

Fácil.

Fonte: Própria (2020).

Com relação ao nível de dificuldade na aprendizagem dos conteúdos de Genética estudados na disciplina de Biologia, 20 (62,5\%) estudantes consideram os conteúdos de genética "Um pouco difícil", oito participantes (25\%) consideram "Muito difícil”, e quatro $(12,5 \%)$ "Fácil", como observado na figura 2; indicando que a maioria destes enfrentam dificuldades em aprender os conteúdos de genética. Araújo, Carvalho, Lima (2016) e Araújo et al. (2018), em trabalhos realizados no município de Floriano-PI, também apontam que a maioria dos estudantes consideram difícil as temáticas estudadas nos conteúdos de Genética.

Figura 2: Nível de dificuldade nos conteúdos de Genética.

32 respostas

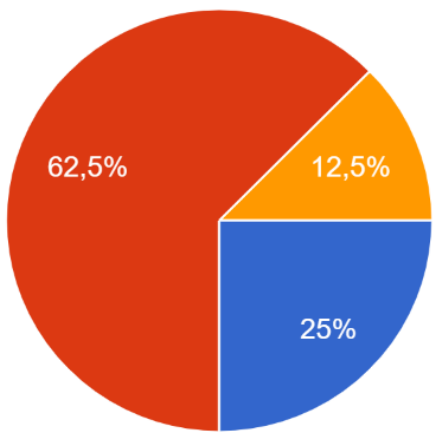

Muito difícil;

Um puco difícil;

Fácil. 


\section{A GENÉTICA DO ENSINO MÉDIO NA PERSPECTIVA DISCENTE}

Fonte: Própria (2020).

Nas respostas relacionadas às principais dificuldades frente aos conteúdos de genética, 11 participantes $(34,4 \%)$ afirmam que a principal delas é a "Dificuldade em matemática", enquanto que dez $(31,3 \%)$ tem como principal dificuldade os "Termos difíceis", cinco $(15,6 \%)$ afirmam não ter dificuldades, quatro (12,5\%) o "Distanciamento da realidade" e dois $(6,3 \%)$ a "Metodologia do professor", como demonstrado na figura 3.

De maneira similar aos resultados, Borges, Silva, Reis (2017) e Borges, Silva, Reis (2016) constatam em seus estudos que os estudantes possuem como dificuldade e desafio na aprendizagem os cálculos aplicados aos exercícios de genética, que às vezes podem até saber resolver, mas não sabem onde se aplica. Por outro lado Souza (2015), ao pesquisar também sobre os motivos dessas dificuldades, encontrou em seu estudo resultados que apontam como principal dificuldade no ensino de Genética os termos técnicos relacionados aos conteúdos.

Figura 3: Causas da dificuldade em aprender Genética.

32 respostas

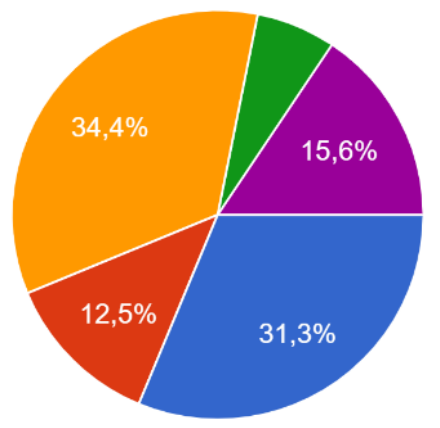

Termos difíceis;

Distanciamento da realidade;

Dificuldade em matemática;

Metodologia do professor;

Não tenho dificuldades.

Fonte: Própria (2020).

Quanto a satisfação nas aulas de Genética (figura 4), 16 (50\%) estudantes afirmam "Gosto igual outros conteúdos de Biologia", 15 (46,9\%) "Gosto menos que outros conteúdos de biologia" e um "Gosto mais que a maioria dos conteúdos em Biologia". Esses resultados refletem a insatisfação decorrente das dificuldades enfrentadas, gerando desinteresse e falta de motivação aos estudantes com os conteúdos de genética quando comparado aos demais conteúdos.

Goulart, Faria (2014), bem como Mascarenhas et al. (2016), apontam em seus estudos que grande parte do desinteresse pela genética vem da ausência de metodologias lúdicas para o ensino desses conteúdos e salientam também que em aulas lúdicas, os estudantes demonstram mais interesse e motivação do que em aulas meramente teóricas. 
Figura 4: Satisfação nos conteúdos de Genética em relação aos demais.

32 respostas

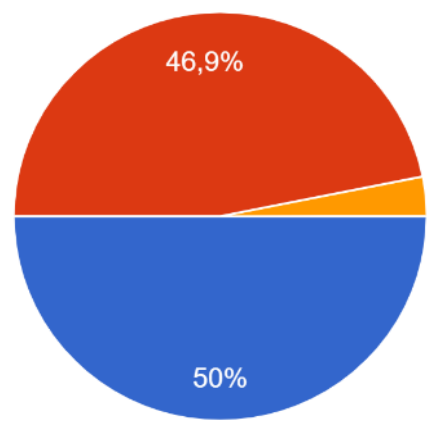

Gosto igual outros conteúdos de biologia;

Gosto menos que outros conteúdos de biologia;

Gosto mais que a maioria dos conteúdos em biologia.

Fonte: Própria (2020).

Sobre as respostas relacionadas à aprendizagem nas aulas de genética, 23 (71,9\%) dos estudantes afirmam que "São boas, mas não consigo aprender" enquanto 9 (28,1\%) afirmam que "São ótimas e consigo aprender". Destacamos aqui que não houve nenhuma resposta "são ruins e o professor não faz nada para melhorar", evidenciando que os participantes não associam seus déficits aos docentes, mas principalmente aos conteúdos pertinentes à disciplina, como evidenciado na figura 5.

Pesquisas relacionadas a aprendizagem de genética (LEAL; MEIRELLES; RÔÇAS, 2019; OLIVEIRA et al., 2017; SOUSA et al., 2016) mostram que a maioria dos estudantes que estão concluindo o Ensino Médio não compreendem o básico sobre as leis de Mendel, apresentando alto percentual de erros quando questionados sobre os conteúdos de genética. Os autores Temp, Santos (2018) em um estudo sobre a importância do ensino e aprendizagem de genética pela ótica de professores de biologia, identificaram que estes consideram o ensino de genética difícil, exigindo do estudante habilidades para compreender e relacionar os conteúdos da genética a conteúdos de outras disciplinas.

Figura 5: Aprendizagem nas aulas de Genética. 
32 respostas

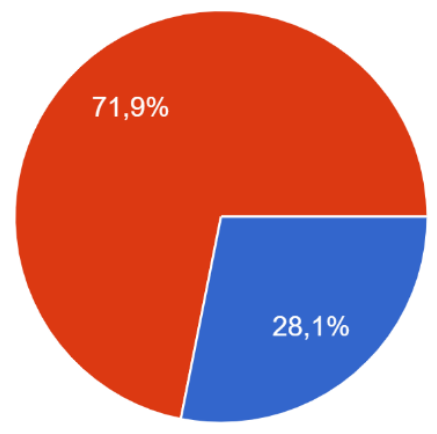

São ótimas e consigo aprender;

São boas mas não consigo aprender;

São ruins e o professor não faz nada pra melhorar.

Fonte: Própria (2020).

Os estudantes também foram questionados em relação aos conteúdos de maior dificuldade na genética e 15 deles (46,9\%) afirmam ser "Sistema ABO/Alelos múltiplos", cinco $(15,6 \%)$ "Herança Quantitativa", cinco $(15,6 \%)$ "Linkage”, quatro $(12,5 \%)$ "Herança Sexual" e três $(9,4 \%)$ " $2^{a}$ Lei de Mendel", conforme observado na figura 6. Resultados de pesquisas realizadas por Matos, Campos (2017) e Vieira (2013) também demonstram dificuldades e incompreensões dos assuntos relacionados ao Sistema $\mathrm{ABO}$, constatados a partir de questionários.

Figura 6: Conteúdo de maior dificuldade na Genética.

32 respostas

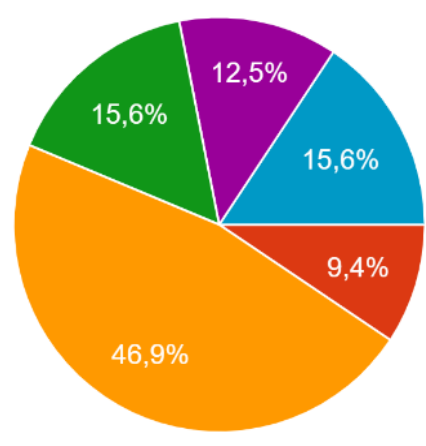

$1^{\circ}$ Lei de Mendel;

$2^{\circ}$ Lei de Mendel;

Sistema ABO/Alelos múltiplos;

Herança Quantitativa;

Herança Sexual;

Linkage.

Fonte: Própria (2020).

Do total de estudantes participantes da pesquisa, $25(78,1 \%)$ afirmam não ter participado de atividades com metodologias lúdicas e apenas 7 (21,9\%) afirmam ter participado de atividades com metodologias lúdicas, demonstrado que a maioria dos docentes utilizam apenas aula expositiva, o que pode estar associado a um problema no ensino dos conteúdos de genética como aponta Oliveira et al. (2017). 
Ainda em seu estudo, Oliveira et al. (2017) ressalta que 84,2\% dos participantes de sua pesquisa afirmaram ter aprendido genética apenas por meio de métodos tradicionais. Essa ausência de metodologias inovadoras demonstra a necessidade de repensar o ensino de genética para que ele aconteça de maneira efetiva e significativa, facilitando a compreensão dos conteúdos trabalhados.

Figura 7: Participação em atividades com metodologias lúdicas.

32 respostas

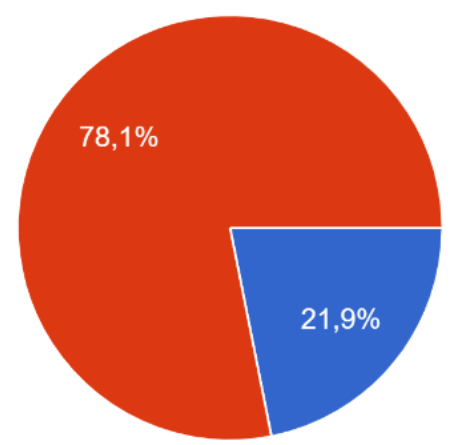

Fonte: Própria (2020).

Quando questionados sobre a melhoria do ensino de genética através de atividades com metodologias lúdicas, 30 estudantes $(93,8 \%)$ afirmaram que haverá qualidade no ensino caso se faça a utilização de metodologias lúdicas e apenas 2 deles $(6,2 \%)$ afirmam que não. Esses resultados estão em concordância com o trabalho de Ferreira et al. (2015a) e Ferreira et al. (2015b) que demonstraram em seus respectivos estudos eficácia da utilização de novas metodologias no ensino de genética. Para Brão, Pereira (2015) e Kenski (2015), é necessária a inovação no ensino de genética, pois o uso do lúdico favorece o aprendizado dos conteúdos e facilita a contextualização com a realidade dos estudantes.

Figura 8: Opinião sobre a melhoria do ensino de genética através de atividades com metodologias lúdicas. 
32 respostas

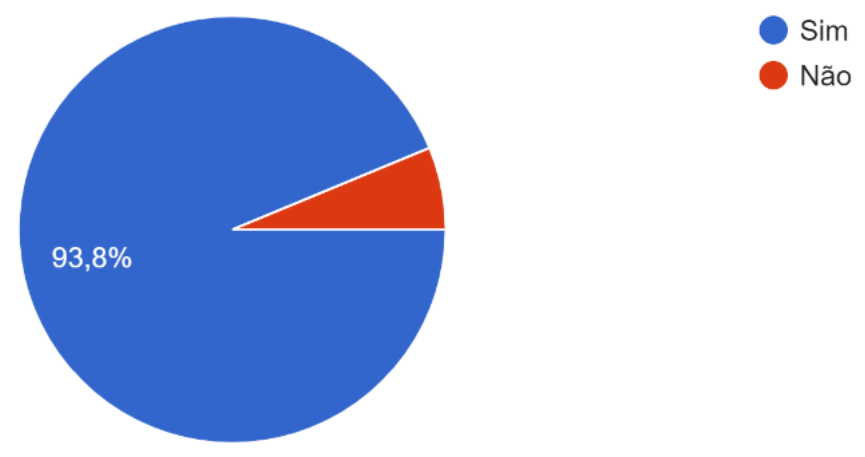

Fonte: Própria (2020).

\section{CONCLUSÕES}

Levando em consideração os resultados obtidos por meio desta pesquisa, constatou-se que a maioria dos estudantes considera os conteúdos de genética difícil e que as dificuldades enfrentadas variam desde a terminologia presente nos conteúdos até a metodologia utilizada pelos docentes; sendo a principal delas, a dificuldade em Matemática, refletindo déficits na aprendizagem em outras disciplinas. De maneira adicional, verificou-se que a maioria dos estudantes não participa de atividades com metodologias lúdicas evidenciando que os docentes ainda se utilizam de métodos tradicionais contribuindo de alguma forma para um baixo desempenho na aprendizagem da genética.

Assim, faz-se necessário que as metodologias utilizadas para aplicação dos conteúdos de genética sejam repensadas afim de proporcionar aos estudantes uma aprendizagem efetiva de modo que compreendam e consigam aplicar tais conhecimentos. Implicando em abordagens mediante a contextualização e metodologias como o uso de maquetes, filmes, jogos e atividade lúdicas evitando a compartimentalização frente a interdisciplinaridade. Por fim, espera-se que os resultados apresentados sirvam como diagnóstico para propostas educacionais de melhoria no processo de ensino-aprendizagem das diversas disciplinas de Biologia, com ênfase nos conteúdos de genética.

\section{REFERÊNCIAS}

ARAUJO, A. B; GUSMÃO, F. A. F. AS PRINCIPAIS DIFICULDADES ENCONTRADAS NO ENSINO DE GENÉTICA NA EDUCAÇÃO BÁSICA BRASILEIRA. In: Encontro Internacional de Formação de Professores, X./ Fórum Permanente Internacional de Inovação Educacional, XI., 2017, Sergipe. Anais eletrônicos... Sergipe: Instituto de Tecnologia e Pesquisa de Sergipe, 2017. p. 1-11. Disponível em: https://eventos.set.edu.br/enfope/article/view/4707/1565 Acesso em: 11 out. 2020. 
ARAUJO, M. dos S.; CARVALHO, B. A. P.; LIMA, M. M. de O. A Genética no ensino médio: uma análise dos conhecimentos dos alunos de escolas públicas da rede estadual e federal em Floriano/PI. In: CONGRESSO NORTE E NORDESTE DE PESQUISA E INOVAÇÃO, XI., 2016, Maceió. Anais eletrônicos... Maceió: Instituto Federal de Alagoas, 2016. p. 2231-2240. Disponível em:

http://connepi.ifal.edu.br/2016/files/anais/2_Ciencias_Biologicas.pdf Acesso em: 14 jul. 2020.

ARAUJO, M. dos S.; FREITAS, W. L. dos S.; LIMA, S. M. de; LIMA, M. M. de O. A GENÉTICA NO CONTEXTO DE SALA DE AULA: DIFICULDADES E DESAFIOS EM UMA ESCOLA PÚBLICA DE FLORIANO-PI. Revista de Ensino de Ciências e Matemática, São Paulo, v. 9, n. 1, p. 19-30. 2018. Disponível em: https://doi.org/10.26843/rencima.v9i1 Acesso em: 14 jul. 2020.

BORGES, C. K. G. D.; SILVA, C. C.; REIS, A. R. H. AS DIFICULDADES DE APRENDIZAGEM DAS LEIS DE MENDEL POR ALUNOS DO ENSINO MÉDIO DE DUAS ESCOLAS DE MANAUS. In: Simpósio Nacional de Ensino de Ciência e Tecnologia - SINECT, V., 2016, Ponta Grossa. Anais eletrônicos... Ponta Grossa: Universidade Tecnológica Federal do Paraná, 2016. Disponível em: http://www.sinect.com.br/2016/selecionados.php?ordem01=titulo\&ordem02=titulo Acesso em: 08 ago. 2020.

BORGES, C. K. G. D.; SILVA, C. C.; REIS, A. R. H. AS DIFICULDADES E OS DESAFIOS SOBRE A APRENDIZAGEM DAS LEIS DE MENDEL ENFRENTADOS POR ALUNOS DO ENSINO MÉDIO. Experiências em Ensino de Ciências, Mato Grosso, v. 12, n. 6, p. 61-75, ago. 2017. Disponível em:

https://if.ufmt.br/eenci/index.php?go=artigos\&idEdicao=58 Acesso em: 14 jul. 2020.

BRÃO, A. F. S.; PEREIRA, A. M. T. B. Biotécnétika: possibilidade do jogo no ensino de genética. Revista Electrónica de Enseñanza e las Ciencias, v. 14, n. 1, p. 55-76, 2015. Disponível em: http://reec.uvigo.es/volumenes/volumen14/REEC_14_1_4_ex826.pdf Acesso em: 14 jul. 2020

BRASIL. Ministério da Educação e do Desporto. Secretaria de Educação Média e Tecnológica. PCN+ Ensino Médio: Orientações Educacionais complementares aos Parâmetros Curriculares Nacionais. Ciências da natureza, matemática e suas tecnologias. Brasília: MEC-SEMTEC, 2002.

COSTA, C. P. F. ENSINO DE GENÉTICA E EVOLUÇÃO PARA ENTENDIMENTO DA DIVERSIDADE. Orientadora: Dra. Mônica Bucciarelli Rodriguez. 2019. $101 \mathrm{f}$. Dissertação (Mestrado em Ensino de Biologia) - Universidade Federal de Minas Gerais, Instituto de Ciências Biológicas, Belo Horizonte, 2019. Disponível em: http://hdl.handle.net/1843/32569 Acesso em: 22 jul. 2020.

DURÉ, R. C.; ANDRADE, M. J. D. de; ABÍLIO, F. J. P. ENSINO DE BIOLOGIA E CONTEXTUALIZAÇÃO DO CONTEÚDO: QUAIS TEMAS O ALUNO DE ENSINO MÉDIO RELACIONA COM O SEU COTIDIANO?. Experiências em Ensino de Ciências, Mato Grosso, v.13, n.1, p. 259-272, abr. 2018. Disponível em:

https://if.ufmt.br/eenci/artigos/Artigo_ID471/v13_n1_a2018.pdf Acesso em: 09 ago. 2020. 
FERREIRA, K. E. et al., Conhecimentos de genética adquiridos por alunos do ensino médio: a necessidade de repensar os processos de ensino e aprendizagem desta disciplina. In: Encontro Regional de Ensino de Biologia. III., 2015, Juiz de Fora. Anais eletrônicos... Juiz de Fora: Universidade Federal de Juiz de Fora - Faculdade de Educação, 2015a. Disponível em: https://sbenbio.org.br/anais-erebio/anais-do-encontro-regional-de-ensino-de-biologiaregional-4/ Acesso em: 10 ago. 2020.

FERREIRA, K. E. et al., Ensino e aprendizagem de genética: estudo em uma escola da rede pública na região metropolitana de Belo Horizonte - MG. In: Encontro Nacional de Pesquisa em Educação em Ciências, X., 2015, Águas de Lindóia. Anais eletrônicos... Águas de Lindóia: Associação Brasileira de Pesquisa em Educação em Ciências, 2015b. p. 1-8. Disponível em: http://www.abrapecnet.org.br/enpec/x-enpec/anais2015/listaresumos.htm Acesso em: 16 jul. 2020.

GOULART, N.M.; FARIA, R.C.B. Ensino de conteúdos de Genética no ensino médio e as contribuições dos objetos de aprendizagem. In: CONGRESO IBEROAMERICANO DE CIENCIA, TECNOLOGÍA, INNOVACIÓN Y EDUCACIÓN, I., 2014, Buenos Aires. Anais eletrônicos... Buenos Aires: IBERTIC, Instituto Iberoamericano de TIC y Educación, 2014. p.01-09. Disponível em: https://www.oei.es/historico/congreso2014/memoriactei/1555.pdf Acesso em: 16 jul. 2020.

KENSKI, V. M. A urgência de propostas inovadoras para a formação de professores para todos os níveis de ensino. Revista Diálogo Educacional, Curitiba, v. 15, n. 45, p. 423-441, 2015. Disponível em:

https://periodicos.pucpr.br/index.php/dialogoeducacional/article/view/1963 Acesso em: 10 ago. 2020.

LA LUNA, A. Importância do Ensino e Aprendizagem de Genética para o Mundo Atual. Revista de Educação, Londrina, v. 17, n. 23, p. 44-53, 2014. Disponível em: https://revista.pgsskroton.com/index.php/educ/article/view/3080 Acesso em: 09out. 2020.

LEAL, C. A.; MEIRELLES, R. M. S. de; RÔÇAS, G. O QUE ESTUDANTES DO ENSINO MÉDIO PENSAM SOBRE GENÉTICA? Concepções discentes baseada na Análise de conteúdo. Revista Eletrônica Científica Ensino Interdisciplinar, Mossoró, v. 5, n. 13, p. 71-86. 2019. Disponível em:

http://periodicos.uern.br/index.php/RECEI/article/view/3110/1930 Acesso em: 21 jul. 2020.

LIMA, J. S. de; SANTOS, V. A. dos; Jogo Leis de Mendel - Ensinando genética de forma lúdica. In: Congresso Brasileiro de Informática na Educação, III., Simpósio Brasileiro de Informática na Educação, XXI., 2014, Dourados. Anais eletrônicos... Dourados: Sociedade Brasileira de Computação - SBC, 2014. p. 677-681. Disponível em: https://www.brie.org/pub/index.php/sbie/article/view/2998 Acesso em: 10 ago. 2020.

MASCARENHAS, M. de J. O.; SILVA, V. C. da; MARTINS, P. R. P.; FRAGA, E. da C.; BARROS, M. C. ESTRATÉGIAS METODOLÓGICAS PARA O ENSINO DE GENÉTICA EM ESCOLA PÚBLICA. Revista Pesquisa em Foco, São Luís, v. 21, n. 2, p. 05-24. 2016. Disponível em:

http://ppg.revistas.uema.br/index.php/PESQUISA_EM_FOCO/issue/view/165 Acesso em: 13 jul. 2020. 
MATOS, A. A. de; CAMPOS, F. L. Jogo didático no ensino médio como facilitador do ensino-aprendizagem do sistema sanguíneo ABO. Revista Espacios, Ciudad de Panamá, v. 38, n. 15, 2017. Disponível em: https://www.revistaespacios.com/a17v38n15/17381507.html Acesso em: 08 ago. 2020.

OLIVEIRA, H. T de. A.; FERREIRA, K. E.; RIBEIRO, P. A de. C.; ROCHA, M. L.; COSTA, F de. J.; MARTINS, E. M. METODOLOGIAS ALTERNATIVAS PARA O ENSINO DE GENÉTICA EM UM CURSO DE LICENCIATURA: um estudo em uma universidade pública de Minas Gerais. Revista da Universidade Vale do Rio Verde, Três Corações, v. 15, n. 1, p. 497-507. 2017. Disponível em:

http://periodicos.unincor.br/index.php/revistaunincor/article/view/2790 Acesso em: 08 ago. 2020.

Organização Mundial de Saúde - OMS. OMS afirma que COVID-19 é agora caracterizada como pandemia. Brasília, 2020. Disponível em: https://www.paho.org/bra/index.php?option=com_content\&view=article\&id=6120:omsafirma-que-covid-19-e-agora-caracterizada-como-pandemia\&Itemid=812 Acesso em: 17 ago. 2020.

PRODANOV, C. C.; FREITAS, E. C. de. Metodologia do trabalho científico [recurso eletrônico]: métodos e técnicas da pesquisa e do trabalho acadêmico. 2. ed. Novo Hamburgo: Universidade Feevale, 2013.

ROCHA, L. S. Estratégias Metodológicas para Ensinar Genética no Ensino Médio. Orientador: Prof. Dr. Fernando Periotto. 2013. 47 f. Monografia (Especialização em Educação: Métodos e Técnicas de Ensino) - Universidade Tecnológica Federal do Paraná, Medianeira, 2013. Disponível em: http://repositorio.roca.utfpr.edu.br/jspui/bitstream/1/4407/1/MD_EDUMTE_2014_2_57.pdf Acesso em: 09 out. 2020.

SANTIAGO, S. A.; CARVALHO, H. F. de. Modelo tridimensional para o ensino da divisão celular. Revista Genética na Escola, Ribeirão Preto, v. 14, n. 2, p. 138-145. 2019. Disponível em: https://7ced070d-0e5f-43ae-9b1c-

aef006b093c9.filesusr.com/ugd/b703be_1f8b08e62e7145fabff0fa429527dc5a.pdf Acesso em: 13 jul. 2020.

SOUSA, E. S.; NUNES-JUNIOR, F. H.; CAVALCANTE, C. A. M.; HOLANDA, D. A. S. A Genética Em Sala De Aula: Uma Análise das Percepções e Metodologias Empregadas por Professores das Escolas Públicas Estaduais de Jaguaribe Ceará. Conexões Ciência e Tecnologia, Fortaleza, v. 10, n. 4, p. 16-24, dez. 2016. Disponível em: http://conexoes.ifce.edu.br/index.php/conexoes/article/view/1106 Acesso em: 22 jul. 2020.

\section{SOUZA, M. de. DIFICULDADES DE ALUNOS DO ENSINO MÉDIO NA}

APRENDIZAGEM DE GENÉTICA. Orientadora: Prof. Dra. Patricia do Rocio Dalzoto. 2015. 27 f. Monografia (Especialização em Genética) - Universidade Federal do Paraná, Foz do Iguaçu, 2015. Disponível em: https://acervodigital.ufpr.br/handle/1884/42247 Acesso em: 14 jul. 2020.

TEMP, D. S.; BARTHOLOMEI-SANTOS, M. L. O ensino de Genética: a visão de professores de Biologia. Revista Científica Schola, Santa Maria, v. II, n. 1, p. 83-95, 2018. 


\section{A GENÉTICA DO ENSINO MÉDIO NA PERSPECTIVA DISCENTE}

Disponível em:

http://www.cmsm.eb.mil.br/images/CMSM/revista_schola_2018/Artigos_alterados/II._1._O_ ensino_de_Gen\%C3\%A9tica_-_a_vis\%C3\%A3o_de_professores_de_Biologia.pdf Acesso em: 12 jul. 2020.

TEIXEIRA, Mirian Vieira; NASCIMENTO, Dandara Lorrayne do. Atividades lúdicas no processo de ensino e aprendizagem dos conceitos de genética. Educação Pública, v. 20, $\mathrm{n}^{\circ}$ 14, 14 de abril de 2020. Disponível em:

https://educacaopublica.cecierj.edu.br/artigos/20/15/atividades-ludicas-no-processo-deensino-e-aprendizagem-dos-conceitos-de-genetica Acesso em: 09 out. 2020.

VIEIRA, M. S. Abordagem genética e imunofisiológica dos sistemas ABO e RH para melhor compreensão e ensino da eritroblastose fetal. Orientador: Dr. Fernando Costa Amaral. 2013. 112 f. Dissertação (Mestrado em ensino de Biologia), Pontifícia Universidade Católica de Minas Gerais, Belo Horizonte, 2013. Disponível em:

http://www.biblioteca.pucminas.br/teses/EnCiMat_VieiraMS_1.pdf Acesso em: 10 ago. 2020. 